\title{
Thrombotic risk in patients with COVID-19
}

\author{
Edoardo Pancaldi ${ }^{1, \dagger}$, Greta Pascariello $^{1, \dagger}{ }^{\dagger}$, Giuliana Cimino ${ }^{1}$, Angelica Cersosimo $^{1}$, Ludovica Amore ${ }^{1}$, Fabio Alghisi ${ }^{1}$, \\ Nicola Bernardi ${ }^{1}$, Emiliano Calvi ${ }^{1}$, Carlo Mario Lombardi ${ }^{1}$, Enrico Vizzardi ${ }^{1}{ }^{*}$, Marco Metra ${ }^{1}$ \\ ${ }^{1}$ Cardiology Unit, Department of Medical and Surgical Specialities, Radiological Sciences and Public Health, University of Brescia, 23123 Brescia, Italy \\ *Correspondence: vizzardi72@gmail.com (Enrico Vizzardi) \\ $\dagger$ These authors contributed equally.
}

\section{DOI:10.31083/j.rcm2202035}

This is an open access article under the CC BY 4.0 license (https://creativecommons.org/licenses/by/4.0/).

Submitted: 29 November 2020 Revised: 28 March 2021 Accepted: 31 March 2021 Published: 30 June 2021

Emerging evidences prove that the ongoing pandemic of coronavirus disease 2019 (COVID-19) is strictly linked to coagulopathy even if pneumonia appears as the major clinical manifestation. The exact incidence of thromboembolic events is largely unknown, so that a relative significant number of studies have been performed in order to explore thrombotic risk in COVID-19 patients. Cytokine storm, mediated by pro-inflammatory interleukins, tumor necrosis factor $\alpha$ and elevated acute phase reactants, is primarily responsible for COVID-19-associated hypercoagulopathy. Also comorbidities, promoting endothelial dysfunction, contribute to a higher thromboembolic risk. In this review we aim to investigate epidemiology and clarify the pathophysiological pathways underlying hypercoagulability in COVID-19 patients, providing indications on the prevention of thromboembolic events in COVID-19. Furthermore we aim to reassume the pathophysiological paths involved in COVID-19 infection.

Keywords

Thrombosis; COVID-19; Pulmonary embolism; Endothelitis; Coagulopathy

\section{Introduction}

Coronavirus disease 2019 (COVID-19) has spread rapidly around the world, with high morbidity and mortality.

The World Health Organization (WHO) has declared COVID-19 a public health emergency of international concern, and, as of 26 April 2021, with 146,689,258 global estimate laboratory confirmed cases and 3,102,410 deaths (https: //www.who.int) [1].

In view of the rapid increase in the number of patients suffering from this unpredictable disease, the aim of physicians working on first line should be to know in depth its pathophysiology, clinical evolution and short and long-term consequences. Today, pneumonia remains the major clinical manifestation of COVID-19 [2] but, however, the onset of the disease have highlighted severe features previously unthinkable in patients, even in young patients with no previous pathology $[3,4]$.

In addition, hospitalized COVID-19 patients frequently develop laboratory abnormalities compatible with hypercoagulability and clinically high prevalence of thromboembolic events [5]. Indeed, pulmonary embolism (PE) is one of the most important parts of the spectrum of clinical manifestations of these patients [6], but left ventricular thrombosis as a rare complication of Takotsubo syndrome has also been reported [7], and extracorporeal circuits and arterial thrombosis [8].

These events appear to be a response to COVID-19 with an exuberant cytokine storm [9]. Immunological studies have also shown that pro-inflammatory cytokines interleukin (IL)-6, IL-17A and tumor necrosis factor $\alpha$ were elevated in most patients with severe outcomes [10].

Pro-inflammatory cytokines are known to be critically involved in abnormal blood clot formation and platelet hyperactivation and also play an important role in the downregulation of important anticoagulant physiological pathways [11].

The purpose of this review is to clarify the pathophysiological mechanism underlying hypercoagulability in COVID19 patients and to provide indications on the correct prevention of thromboembolic events to reduce the morbidity and mortality rate.

Furthermore we aim to reassume the pathophysiological paths involved in COVID-19 infection.

\section{Methodology}

In this review we analyze the most recent research article, reviews and case reports about COVID-19, found on PubMed and published in several scientific journals.

\subsection{Epidemiology}

Since we are witnessing a novel and still ongoing COVID19 pandemic, there is yet lack of a clear awareness of thrombotic risk. To date, several studies attempted to examine the epidemiology of venous thromboembolism (VTE), PE, deep venous thrombosis (DVT), arterial thrombosis and bleeding in COVID-19.

In literature, a substantial risk of VTE in COVID-19 patients is described especially with regard to Intensive Care Unit (ICU), where PE may emerge in up to one-third of severally ill patients [12]. Bompard et al. [13] stated a 24\% cumulative incidence of PE, 50\% in ICU patients and $18 \%$ in other patients despite receiving prophylactic anticoagulation. Interestingly, Poissy et al. [14] compared patients with COVID19, admitted in ICU from February to March 2020, and patients with Influenza, admitted in ICU for respiratory fail- 
ure during the same time interval in 2019; the frequency of PE in COVID-19 cases was doubly as high as the frequency observed in patients suffering from Influenza in 2019 (20.6\% versus $7.5 \%)$.

In a single-centre cohort study of 198 patients admitted for COVID-19 and treated with thrombosis prophylaxis, VTE was observed in 39 of 198 patients (20\%) [6.6\% of PE and $13 \%$ of DVT]. In the ICU, the cumulative incidence of VTE was even higher, reaching 47\% [15]. The analysis of different risk factors among this cohort revealed that a higher white blood cell count, higher D-dimer level and higher neutrophilto-lymphocyte ratio was independently associated with VTE, underlining the tight relationship between coagulation and inflammatory pathways.

Also comorbidities, such as diabetes, hypertension and acute kidney injury, play a role promoting endothelial damage and may be, consequently, linked to COVID-19-related complications [16]. Noteworthy, an Italian study compared clinical characteristics and outcomes between COVID-19 patients with concomitant cardiac disease and subjects not affected by cardiac diseases. They noted a high proportion of mortality, septic shock and thromboembolic events in cardiac patients (23\% versus 6\%) [17].

Llitjos et al. [18] carried out a backward looking study in two French ICU, finding a surprisingly significant percentage of thromboembolic events (around 56\%) in COVID-19 patients who were receiving therapeutic anticoagulation, suggesting to consider an early therapeutic anticoagulation in critically ill COVID-19 patients.

In a cohort of 184 ICU patients affected by COVID-19 pneumonia and admitted in three hospitals in the Netherlands, a radiographically confirmed VTE was reported in $27 \%$ of the patients, with $\mathrm{PE}$ as the most recurring thrombotic complication (13.6\%), and arterial events occurred in $3.7 \%$ of the patients. All the above events took place despite the usage of standard doses thromboprophylaxis [19].

A $21 \%$ cumulative rate of VTE events (corresponding to a rate of $7.7 \%$ among closed cases) was reported in an Italian single-centre retrospective cohort study, ranging from a cumulative rate of $27.6 \%$ in ICU and $6.6 \%$ in patients on the general ward [20], comparable to the incidence of VTE (25\%) reported in a ICU in Wuhan, China where patients were, however, not on anticoagulant therapy [21]. Conversely, a lower rate of radiographically confirmed VTE was reported in an American multicentre retrospective study of 400 COVID-19 hospitalized patients and mainly treated with standard-dose prophylactic anticoagulation $(4.8 \%$ confirmed VTE, with a VTE rate of $3.1 \%$ in non critically ill patients and $7.6 \%$ in ICU). Arterial thrombosis rate was $2.8 \%$ (1.2\% in non critically ill patients and $5.6 \%$ in ICU) while, interestingly, bleeding rate was $4.8 \%$ (3.1\% in non critically ill patients and $7.6 \%$ in ICU), pointing out the urgent need of randomized trials to establish the best anticoagulant treatment in this pathology. Interestingly, the group affected by thrombotic complications had systematically higher D-dimer, fibrinogen, C- reactive protein (CRP), ferritin and procalcitonin, whereas the bleeding complications group had higher procalcitonin and peak D-dimer and lower platelet counts [22].

A multicentre registry (CORONA-VTE), composed of 1114 COVID-19 patients, was filled in to estimate the frequency of arterial or venous thromboembolic disease and major adverse cardiovascular events. It showed a higher occurrence of the above events over 30 days in patients admitted in ICU, in spite of a nearly $90 \%$ use of thromboprophylaxis. They observed a rate of $35.3 \%$ regarding major arterial or venous thromboembolic event and a rate of $45.9 \%$ regarding major cardiovascular events in ICU patients, followed by the hospitalized non-intensive care cohort, with a rate of $2.6 \%$ regarding major arterial or venous thromboembolic event and a rate of $6.1 \%$ regarding major cardiovascular events, and the outpatients, with a rate of $0 \%$ for both [23].

To assess the burden of asymptomatic DVT in COVID-19 patients with elevated D-dimer levels, an observational study, performed in Madrid, described a high incidence (14.7\%) of asymptomatic DVT [24].

In conclusion, given the retrospective nature of the studies and the relatively short follow-up, which may underestimate the real incidence of thromboembolic disease in COVID-19 patients, we can reasonably assert that an accurate incidence is difficult to establish. Several reviews and meta-analysis tried to evaluate the incidence of VTE in COVID-19 showing that VTE incidence, among hospitalized COVID-19 patients, is significant, even in patients undergoing anticoagulant therapy [12, 25-29] (Tables 1,2,3,4).

In agreement with this assumption, randomized trials are needed to determine the realistic picture of an eventual lifethreatening complication of COVID-19.

In this perspective, VTE-COVID is an ongoing trial evaluating the augmented risk of VTE in patients recovered in ICU and in general ward for COVID-19.

\subsection{Pathophysiology of hypercoagulability in COVID-19}

The main entry point into cells for SARS-CoV-2 is angiotensin converting enzyme 2 (ACE-2), which is attached to the outer surface of cells in lungs, arteries, heart, kidney and intestines. The binding of spike S1 protein to ACE-2 causes endocytosis. Furthermore, some studies demonstrated that SARS-CoV-2 can not only infect cells through ACE-2 receptors, but there are also other pathways. In fact, some authors report that there might be another pathway on the surface of red blood cells (RBC) that interact with S1 spike protein. In particular, they demonstrated that $\mathrm{S} 1$ spikes interact with RBC Band3 protein, similarly to the interaction of S1 spikes and ACE-2 receptors. This can determine a capture of oxygen, causing low levels of oxygen in blood: hypoxia.

In patients with severe acute respiratory syndrome coronavirus 2 (SARS-CoV-2) a key role is played by inflammatory response, signalling the progression of COVID-19, as proved in a Chinese retrospective study in which the plasmatic levels of IL-6 (the paramount trigger of the so called 'cytokine storm') and C-reactive protein (CRP) have been found 
Table 1. Published studies describing the epidemiology of thrombotic risk in COVID-19 patients.

\begin{tabular}{|c|c|c|c|c|c|c|c|c|}
\hline References & Date & Number of patients & $\begin{array}{l}\text { Venous thromboem- } \\
\text { bolism }\end{array}$ & $\begin{array}{l}\text { Major arterial or venous } \\
\text { thromboembolic event }\end{array}$ & Pulmunary embolism & $\begin{array}{l}\text { Deep venous throm- } \\
\text { bosis }\end{array}$ & Arterial trhombosis & Bleeding events \\
\hline Al-Samkari et al. [22] & $2020.03-2020.04$ & 400 (144 critically ill) & $4.8 \%(7.6 \%$ in critically & & - & - & $2.8 \%(1.2 \%$ non criticaly & $4.8 \%$ ( $3.1 \%$ non criticaly \\
\hline & & & ill patients) & & & & ill; 5.6\% critically ill) & ill; 7.6\% critically ill) \\
\hline Piazza et al. [23] & $2020.03-2020.04$ & 1114 (170 critically ill) & $\begin{array}{l}4.6 \% \text { ( } 27 \% \text { in critically } \\
\text { ill paients) }\end{array}$ & $\begin{array}{l}5.9 \%(35.3 \% \text { in critically ill } \\
\text { paients) }\end{array}$ & $\begin{array}{l}0.7 \%(1.8 \% \text { in critically } \\
\text { ill paients) }\end{array}$ & $\begin{array}{l}3.5 \%(22.9 \% \text { in criti- } \\
\text { cally ill paients) }\end{array}$ & - & - \\
\hline Lodigiani et al. [20] & $2020.02-2020.04$ & 362 (48 critically ill) & $\begin{array}{l}4.4 \% \text { ( } 8.3 \% \text { in critically } \\
\text { ill paients) }\end{array}$ & $\begin{array}{l}7.7 \%(16.7 \% \text { in critically ill } \\
\text { paients) }\end{array}$ & $\begin{array}{l}2.8 \%(4.2 \% \text { in critically } \\
\text { ill patients) }\end{array}$ & $\begin{array}{l}1.7 \% \text { ( } 4.2 \% \text { in critically } \\
\text { ill patients) }\end{array}$ & - & - \\
\hline Klok et al. [19] & 2020.03-2020.04 & 184 critically ill & $27 \%$ & - & $13.6 \%$ & - & $3.7 \%$ & - \\
\hline Middeldorp et al. [15] & $2020.03-2020.04$ & 198 (75 critically ill) & $\begin{array}{l}20 \% \text { ( } 47 \% \text { in critically } \\
\text { ill patients) }\end{array}$ & - & $\begin{array}{l}6.6 \%(15 \% \text { in critically } \\
\text { ill patients) }\end{array}$ & $\begin{array}{l}13 \% \text { ( } 32 \% \text { in critically } \\
\text { ill patients) }\end{array}$ & - & - \\
\hline Poissy et al. [14] & $2020.02-2020.03$ & 107 critically ill & - & - & $20.6 \%$ & $4.7 \%$ & - & - \\
\hline Bompard et al. [13] & $2020.03-2020.04$ & 135 (24 critically ill) & - & - & $\begin{array}{l}24 \% \text { ( } 50 \% \text { in critically } \\
\text { ill patients) }\end{array}$ & - & - & - \\
\hline Cui et al. [21] & 2020.01-2020.03 & 81 critically ill & $25 \%$ & - & - & - & - & - \\
\hline Demelo Rodriguez et al. [24] & 2020.04 & 156 critically ill & - & - & - & $14.7 \%$ & - & - \\
\hline Llitjos et al. [18] & $2020.03-2020.04$ & $\begin{array}{l}26 \text { critically ill ( } 18 \text { on thera- } \\
\text { peutic anticoagulation) }\end{array}$ & $\begin{array}{l}69 \% \text { ( } 56 \% \text { on therapeu- } \\
\text { tic anticoagulation) }\end{array}$ & - & $\begin{array}{l}23 \% \text { ( } 33 \% \text { on therapeu- } \\
\text { tic anticoagulation) }\end{array}$ & - & - & - \\
\hline Inciardi et al. [17] & 2020.03 & $\begin{array}{l}99 \text { ( } 43 \text { patients with cardiac } \\
\text { history) }\end{array}$ & $\begin{array}{l}12 \%(17 \% \text { in cardiac } \\
\text { patients) }\end{array}$ & & - & - & $\begin{array}{l}3 \%(6 \% \text { in cardiac pa- } \\
\text { tients) }\end{array}$ & \\
\hline
\end{tabular}

Table 2. Reviews and Meta-Analysis describing epidemiology of thrombotic risk in COVID-19 patients.

\begin{tabular}{lcccc}
\hline References & Number of studies & Venous thromboembolism & Pulmonary embolism & Deep vein thrombosis \\
\hline Sakr et al. $[12]$ & 17 studies (5884 patients) & - & $2.6-8.9 \%$ & - \\
Lu et al. $[25]$ & 23 studies (2747 patients) & $21 \%$ & $15 \%$ & $27 \%$ \\
Zhang et al. $[26]$ & 17 studies (1913 patients) & $25 \%$ & $19 \%$ & $7 \%$ \\
Desai et al. $[27]$ & 9 studies (3066 patients) & - & $15.8 \%$ & - \\
Porfidia et al. $[28]$ & 30 studies (3487 patients) & $26 \%$ & $12 \%$ & $14 \%$ \\
Di Minno et al. [29] & 20 studies (1988 patients) & $31.3 \%$ & $18.9 \%$ & $19.8 \%$ \\
\hline
\end{tabular}


Table 3. Percentage of anticoagulation therapy reported in reviews analyzed.

\begin{tabular}{lc}
\hline References & Percentage of patients on anticoagulation therapy \\
\hline Sakr et al. [12] & - \\
Lu et al. [25] & $33.8 \%$ \\
Zhang et al. [26] & - \\
Desai et al. [27] & - \\
Porfidia et al. [28] & $73.2 \%$ prophylactic doses \\
& $81 \%$ intermediate doses \\
Di Minno et al. [29] & $16.8 \%$ therapeutic doses \\
\hline
\end{tabular}

to be independent predictive factors of the disease severity in COVID-19 patients [30]. Inflammatory response leads to severe complications and contribute to COVID-19-associated hypercoagulability. Coagulation disorders frequently occur in COVID-19 patients. In the first American autopsy series of COVID-19-related deaths, the main pulmonary findings included thrombosis and microangiopathy in the small pulmonary vessels and capillaries, whereas cardiac involvement did not show lymphocytic myocarditis but only individual cell necrosis [31].

During hospitalization time, in fact, elevated fibrinogen, ferritin, prothrombin time (PT) and D-dimer levels (a fibrin catabolite, released when plasmin cleaves cross-linked fibrin) were noted [32], outlining an hypercoagulable state. Moreover, plasma D-dimer measurement is considered as a direct prognostic marker in SARS-CoV-2 disease and appears to be higher in patients with severe SARS-CoV-2 compared to patients without severe disease [33].

Most of the available D-dimers assays have also been developed to have the best reproducibility around the threshold value used for excluding deep vein thrombosis and/or pulmonary embolism, which is usually around $500 \mathrm{ng} / \mathrm{mL}$. Therefore, their performance at higher values, such as those proposed for initiating high dose anticoagulation in COVID19 patients (i.e., over $3000 \mathrm{ng} / \mathrm{mL}$ ), is probably suboptimal and would need to be assessed in order to avoid the use of inaccurate results in these patients [34].

Methods used to assess thrombin generation and fibrinolysis have also significant limitations that should be considered [34].

Interestingly, novel surveys emphasize the emerging role of endothelial cells damage in COVID-19 patients. Guervilly and coworkers first provide in vivo evidence of endothelial injury. Among ninety-nine patients with COVID-19, they measure circulating endothelial cells (CEC) detached from damaged vessels. Noteworthy, higher levels of CEC positively correlated with admission in ICU, length of hospitalization, disease severity and inflammatory cytokines whereas they inversely correlated with platelet and lymphocyte counts [35]. Interestingly, CEC can be considered non-invasive biomarkers of disease severity in COVID-19 and get the chance for therapies targeting the endothelium.

The pathogenesis of the disease is the following: SARS-
Table 4. Percentage of anticoagulation therapy reported in studies analyzed.

\begin{tabular}{ll}
\hline References & Use of anticoagulation therapy \\
\hline & None (mechanical thromboprophylaxis): \\
& $3.5 \%$ in patients not critically ill \\
& $1.4 \%$ in critically ill \\
& Standard prophylactic anticoagulation: \\
& $89.9 \%$ in not critically ill \\
& $86.1 \%$ in critically ill \\
Al-Samkari et al. [22] & \\
& $6.6 \%$ in not critically ill \\
& $12.5 \%$ in critically ill \\
& Thromboprophylaxis: \\
& $84.8 \%$ in not critically ill \\
& $89.4 \%$ in critically ill \\
& Therapeutic anticoagulation: \\
& $11.5 \%$ in not critically ill \\
& $25.3 \%$ in critically ill \\
\hline
\end{tabular}

CoV-2 can directly invade the vascular endothelium expressing ACE-2; infected cells undergo pyroptosis contributing to the release of danger-associated molecular patterns (DAMPs) and initiate the release of cytokines and chemokines. The activated endothelium upregulates the expression of Von Willebrand factor (VWH) and adhesion molecules including intercellular adhesion molecule (ICAM)-1, $\alpha \mathrm{v} \beta 3$, P-selectin and E-selectin, involving platelets and leukocytes and complement activation [35]. Neutrophils release neutrophil extracellular traps (NETs), a part of DNA with neutrophils granule proteins, such as myeloperoxidase (MPO), cathepsin $\mathrm{G}$, and neutrophil elastase, causing direct activation of the contact pathway $[36,37]$. NETs, in fact, is the primary defensive mechanism leading to invasion of pathogens. They are also involved in the pathogenesis of arterial and venous thrombosis in addition to sepsis, disseminated intravascular coagulation, systemic lupus erythematosus, preeclampsia and vasculitis [38]. In a picture of thrombosis, the release of the highly negatively charged NETs can trap erythrocytes and activate platelets [39]. Moreover, NETs are the trigger of coagulation through inhibition of tissue factor pathway, increasing endothelial and monocyte tissue factor and degrading the anticoagulant protein. However, histones activate platelets throughout Toll-like receptors 2 and 4 and facilitate fibrin formation, while the contact activation system, via FXII activation, is started off by negatively charged DNA and activated platelets by the release of inorganic polyphosphate (PolyP) from platelet dense granules $[38,39]$. The activation of factor XII has important proinflammatory features as its ability to liberate the generation of bradykinin, to upregulate neutrophil function, to generate monocyte-derived proinflammatory chemokines (IL-1 $\beta$, CXCL4, CXCL7, and CCL5), growth factor, and cytokines (IL-1, IL-8, RANTES, IL-6, and MCP-1) [40, 41], but, above all, it initiates coagulation too. These mechanisms have the consequence in excess thrombin generation, which improve the activation of 
platelets, leukocytes, and endothelium by protease-activated receptors (PARs) and result in the formation of a fibrin clot $[36,42]$. The role of complement in thrombosys and inflammation in COVID-19 was investigated by Skendros et al. providing the proof that complement activation potentiates the platelet/NETs/tissue factor/thrombin axis in SARS-CoV-2 infection. The above findings lay the groundwork for a wider use of the C3-targeted therapeutic AMY-101 (now available as compassionate use and objective of an ongoing trial assessing its impact in severe COVID-19 patients) in critically ill patients [43].

Nougier et al. [44] assessed the fibrinolytic activity and thrombin generation in 78 COVID-19 patients and observed a high thrombin generation capacity which remained within normal values despite anticoagulation therapy and a hypofibrinolysis state associated with increased PAI-1 levels.

Critical patients could have a slightly longer PT than patients with more favorable prognosis. APTT is less prolonged than PT, probably due to an increased concentration of factor VIII, which is an acute phase reactant $[45,46]$.

Therefore we can summarize the prothrombotic effect of SARS-CoV-2 infection in:

(1) Facilitation of extensive deposition of the terminal complement components, membrane attack complex C5b9 and $\mathrm{C} 4 \mathrm{~d}$, in addition to the mannose-binding lectinassociated serine protease (MASP-2) within the microvasculature resulting in a release of endothelial cytokines, such as IL-1, IL-8, RANTES, IL-6, and MCP-1, and in an up regulation of the expression of endothelial adhesion molecules, such as VWF and P-selectin [47].

(2) Excessive formation NETs by neutrophils' release [36, 48].

(3) Directly interaction with platelets' TLR-7 and the fragment crystallisable gamma receptor IIa (Fc $\gamma$ RIIA) [42] which can translate into:

-Thromboinflammatory response throughout thrombin that activates endothelial cells by endothelial PAR-1, leading to up regulation of platelet-activating factor (PAF), IL-6, IL8 , and monocyte chemoattractant protein (MCP)- 1 in addition to the adhesion molecules E-selectin, P-selectin, and intercellular adhesion molecule (ICAM)-1 [36].

-Increasing of B-cell immunoglobulin (Ig) G1, IgG2, and IgG production [49] with potentially development of antiphospholipid antibodies, such as anti- $\beta 2$ glycoprotein IgG antibodies [50].

- Facilitating the recruitment of T lymphocytes to sites of vascular injury or infection [51].

All of the above explains that:

(1) VTE in patients with SARS-CoV-2 infection appears highly expanded. Indeed, the cumulative incidence of VTE is reported to be between $25 \%$ and $49 \%$ of patients with severe SARS-CoV-2 infection with PE being the most common thrombotic complication [23].

(2) Arterial thromboembolism Is increased [36].

(3) Acute myocardial injury and myocarditis usually com- plicates the clinical course of severe SARS-CoV-2 infection and it is linked in up to $20 \%$ of hospital presentations with an adverse impact on mortality $[52,53]$.

(4) Increased microvascular thrombosis, especially pulmonary microvascular thrombosis has been previously described in autopsies as a complication of severe acute respiratory distress syndrome (ARDS) [33, 54].

(5) Thrombocytopenia is present in severe cases, caused by direct infection of bone marrow cells with inhibition of platelet synthesis, platelet destruction by the immune system and aggregation in the lungs, resulting in blood clot and platelet consumption [55].

In Fig. 1 coagulation cascade is illustrated and in Fig. 2 the cytokine storm, involved in thrombus generatfion, is reassumed.

\subsection{Therapeutic anticoagulation}

As described before, COVID-19 is a viral infection that, resulting in cytokine storm and systemic inflammatory response, can determine a thrombotic risk and coagulopathy (Table 5). Different reports in the literature of elevated risk of thrombosis during COVID-19 infection have determined the empiric use of anticoagulant drugs for hospitalized patients [56].

A study of the Hubei province in China demonstrates that, without anticoagulation, 25\% of COVID-19 patients developed lower extremity DVT as assessed by doppler ultrasound of lower extremities [23].

We must consider that acutely ill patients, with or without COVID-19, poses several risk factor for thromboembolism. Moreover, there can be additional risk factors for VTE such as age, cancer, obesity, pregnancy, diabetes, congestive heart failure, and history of prior VTE.

In some early studies conducted in acutely ill medical patients, a prophylaxis anticoagulation reduced the incidence of venous thromboembolism up to $60 \%$, without increasing major bleeding risk [57].

An Italian study described thromboembolic events in $7.7 \%$ of patients admitted with COVID-19, estimating a cumulative rate of $21 \%$ [21].

The study by Klok et al. [21] described 25 symptomatic VTE events in 184 adult patients affected by COVID-19, all of whom was receiving VTE prophylaxis. VTE was reported in $27 \%$ of patients, arterial thrombotic events in $3.7 \%$, PE was the most frequent thrombotic complication in $81 \%$. Thus, this study demonstrates that critically ill adults with COVID19 on standard pharmacologic VTE prophylaxis may develop a thromboembolic event.

Another French study conducted among 150 patients with COVID-19 and ARDS receiving prophylactic or empiric treatment dose anticoagulation described that $16.7 \%$ of patients developed pulmonary embolism [58].

For acute COVID-19 patients over age 50 or with medical problems an early treatment regimen with anti-thrombotic agents should be started the first day of illness [59]. 


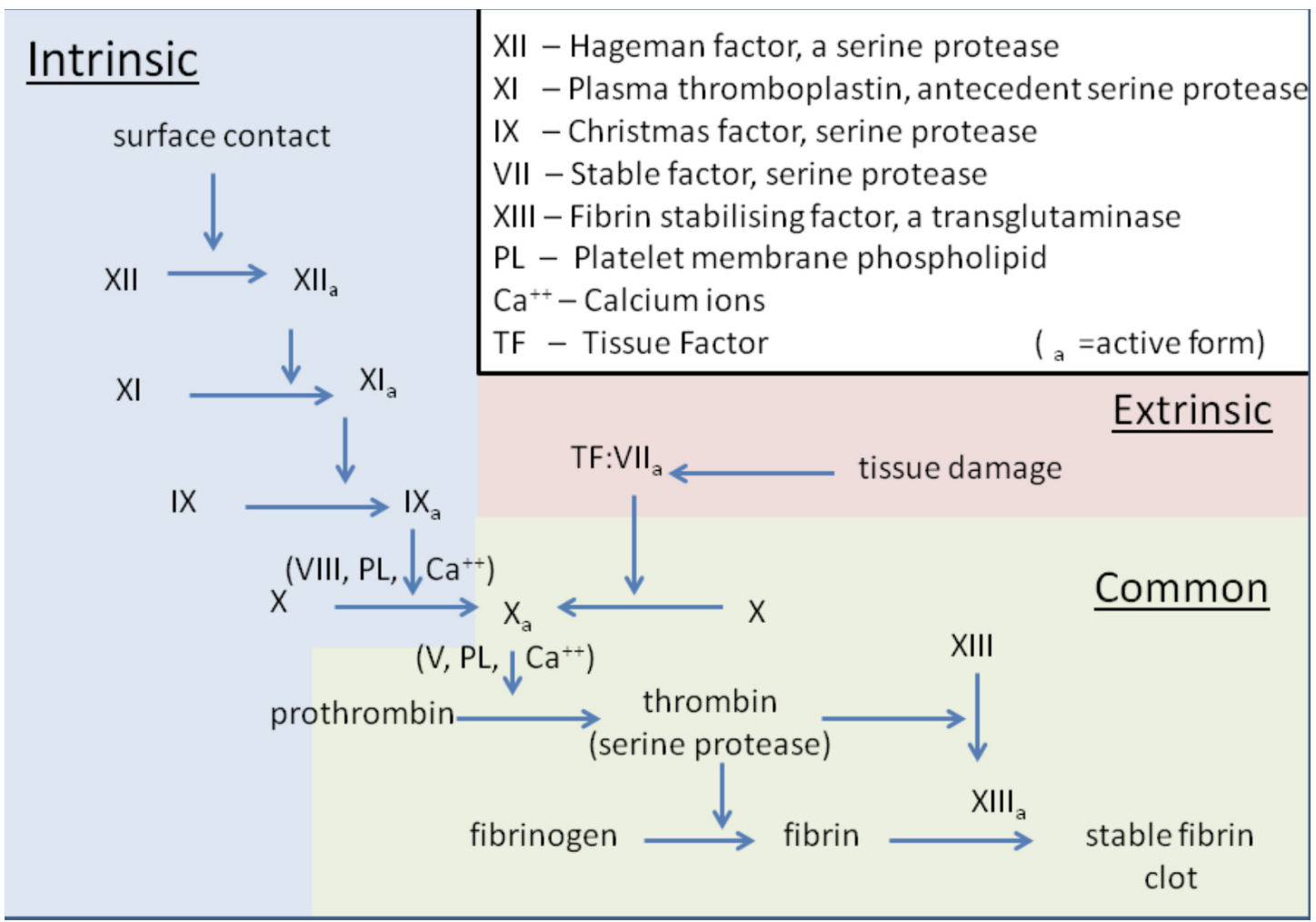

Fig. 1. Coagulation cascade.This figure represents the coagulation cascade: in the intrinsic way the surface contact activates the XII factor, which transforms the XI factor to the X factor; in the extrinsic way a tissue damage activates the VII factor which activates the X factor which transforms the prothrombin into thrombin and the fibrinogen into fibrin and creates a stable fibrin clot.

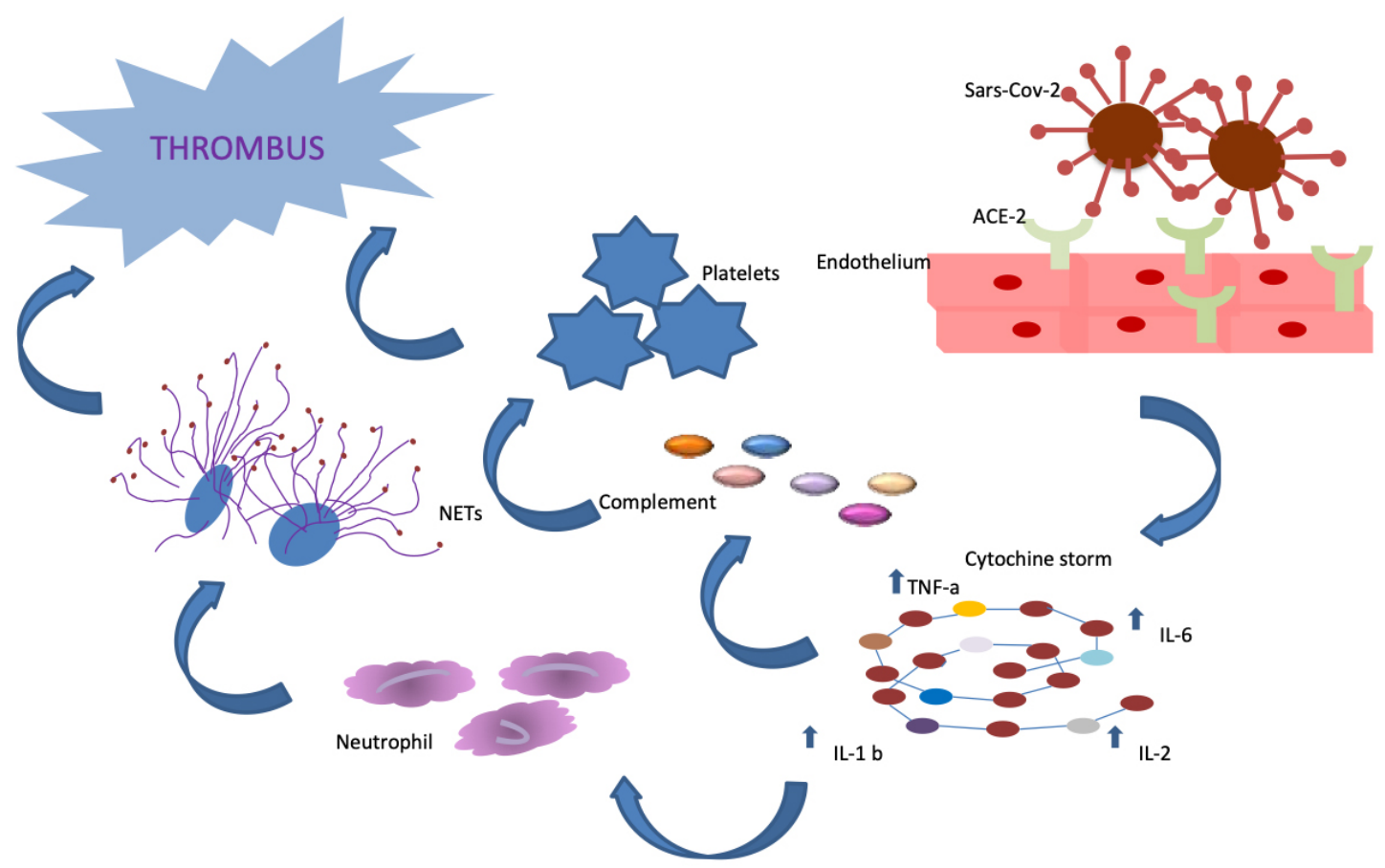

Fig. 2. Cytokine storm involved in thrombus generation. This figure represents the cytokine storm involved in thrombus generation: the SARS-CoV 2, through ACE-2 receptor, induces a cytokine storm, releasing TNF-a, IL-6, IL-2, IL-1b. These factors induce an activation of complement and neutrophils, causing the platelets aggregation and the thrombus generation. 
Table 5. COVID-19 associated Coagulopathy (CAC).

COVID-19 associated Coagulopathy (CAC)

Coagulopathy is characterized by elevated levels of fibrinogen, D-dimer and low variations in the value of PT, aPTT and platelets count

Levels of IL-6 is correlated with levels of fibrinogen

Coagulopathy seems to be correlated to the severity of infection

Elevated levels of D-dimer at the time of hospitalization is associated to an increased mortality

The increasing of D-dimer levels precedes multi-organ failure and DIC

Bleeding events are not common

Thus, in critically ill patients with COVID-19 an intensified prophylaxis regimen may be safer and there is no evidence for use of biomarkers such as D-dimer or fibrinogen to guide the intensity and duration of anticoagulant therapy [60].

The European Society of Cardiology described an anticoagulation algorithm: for high thrombotic risk patients, as those with dyspnea, respiratory rate $>24$, oxygen saturation $<90 \%$, elevated CRP, high D-dimer levels and elevated fibrinogen levels anticoagulation strategies should be considered [61].

A recent study by Ruocco et al. [62] conducted among Italian patients hospitalized for COVID-19 infection, showed that $\mathrm{CHA}(2) \mathrm{DS}(2)-\mathrm{VASc}$ risk score for thromboembolic events can be used for risk stratification for complications and death. In particular, patients with higher CHA(2)DS(2)VASc scores had a higher rates of mechanical ventilation or death and should be considered for anticoagulant treatment.

Tang et al. [63] described 449 patients with severe COVID-19 infection and reported a reduction in mortality with anticoagulant therapy in patients with high D-dimer and/or high sepsis-induced coagulopathy (SIC) score. Another study in New York conducted among 2773 COVID-19 patients reported an improvement of median survival with anticoagulant therapy, especially in mechanically ventilated patients [64].

On 11 April 2020, the Swiss Society of Hematology published recommendations that all in-hospital COVID-19 patients should receive thromboprophylaxis, which echoed the International Society of Thrombosis and Haemostasis (ISTH) guidelines [65]. The ISTH proposed a new method for identify an earlier phase of sepsis-associated disseminated intravascular coagulation (DIC), called SIC. The factors included in this ISTH scoring system are: platelets count, INR, SOFA score.

During hospitalization it is suggested to use low molecular weight heparin (LMWH) over unfractioned heparin (UFH) for the treatment of confirmed or suspected VTE, in order to avoid laboratory monitoring, minimize nursing and phlebotomy exposure.

The WHO interim guidance statement recommends prophylactic daily LMWH or twice daily UFH [66]. The use of $\mathrm{UFH}$ is recomended in patients with creatinine clearance $<15$ $\mathrm{mL} / \mathrm{min}$. A gradual decline of D-dimer levels suggests the response to therapy [23]. An increased plasma D-dimer con- centration during thromboprophylaxis should guide in the administration of higher doses of anticoagulants.

Hermans et al. [67] suggested that it would be appropriate to shift patients on vitamin $\mathrm{K}$ antagonist (VKA) to a directacting oral anticoagulant (DOAC) to reduce the number of needed laboratory testing. This cannot be applied to patients with mechanical valve or anti phospholipid syndrome.

Furthermore, it is important to pay attention to DOACs interactions with antiretroviral drugs and to patients unstable kidney function.

Consideration for risk of VTE in pregnant patients with COVID-19 deserves a great attention. The risk of VTE during pregnancy and postpartum period is increased [68]. Although limited data are available, pregnant women with COVID-19 infection have an high risk of VTE.

There is no evidence for extended VTE prophylaxis in COVID-19 patients after hospital discharge: Barnes et al. [56] suggested that extended VTE prophylaxis is not necessary for all patients with COVID-19 being discharged from hospital. However, a multidisciplinary discussion may be necessary at discharge for patients with multiple VTE risk factors. After hospital discharge from an acute illness, extended prophylaxis with LMWH or DOAC can reduce the risk of VTE, at the cost of increasing bleeding events [69-71].

Spyropoulos et al. applied the modified IMPROVE VTE score to the MAGELLAN subpopulation to investigate whether an elevated D-dimer level could identify a high VTE risk subgroup. This study showed that the modified IMPROVE VTE score with an elevated D-dimer identifies a threshold higher VTE risk subpopulation where benefits are achieved from anticoagulation with rivaroxaban [72].

It is reasonable to employ individualized risk stratification for thrombotic and hemorrhagic risk. It has been reported that patients with high bleeding risk can have also an high ischemic risk [73].

The role of thromboprophylaxis for patients in quarantine with mild COVID-19 but with important comorbidities or for patients is uncertain.

Cohen et al. demonstrated that in acutely ill medical patients, rivaroxaban was non-inferior to enoxaparin for standard-duration thromboprophylaxis. In an extendedduration thromboprophylaxis rivaroxaban reduced the risk of venous thromboembolism, but it was associated with an increased risk of bleeding [74]. 
APEX trial found that among acutely ill medical patients with high D-dimer levels, there was no significant difference between extended-duration betrixaban and a standard regimen of enoxaparin in asymptomatic proximal DVT and symptomatic VTE [74]. Thus, if post discharge prophylaxis seems to be reasonable, approved agents as betrixaban or rivaroxaban or enoxaparin can be used. The duration of anticoagulant therapy is the one indicated in the clinical trials (enoxaparin $40 \mathrm{mg}$ OD for 6-14 days; rivaroxaban $10 \mathrm{mg}$ OD for 31-39 days; betrixaban $160 \mathrm{mg}$ OD for 35-42 days).

In the clinical guidance on the diagnosis, prevention and treatment of venous thromboembolism in hospitalized patient with COVID-19, Spyropoulos et al. [75] suggested that, for those who are at low bleeding risk and with VTE risk (advanced age, cancer, prior history of VTE, thrombophilia, immobility, D-dimer $>2$ times ULN) and IMPROVE VTE score $>4$, an extended thromboprophylaxis with LMWH or DOACs for at least 2 weeks up to 6 weeks post-hospital discharge can be reasonable.

Relatively to the use of thrombolytic therapy, the case of some patients with COVID-19 and ARDS treated with Alteplase $50 \mathrm{mg}$ has been reported and has demonstrated an improvement in oxygenation [76]. However Chatterjee et al. [77] demonstrated that systemic administration of thrombolytic therapy increased major bleeding and intracranial hemorrhage rates.

Recent studies have investigated the effect of inhibition of complement, which is a key player of protective immunity against pathogens, but its excessive or deregulated activation may result in collateral tissue injury [78]. So far, complement inhibitors are currently only used in rare human diseases.

In conclusion, for not hospitalized patients affected by obesity, previous VTE, tumors, with asymptomatic COVID19 , the use of prophylactic dose of LMWH must be considered, using validate risk scores for hospitalized patients (Padua Score $>4$ ). The most recent consensus documents underline the recommendation for a prophylactic dose of LMWH in all hospitalized patients with COVID-19, with the exception of the presence of severe low platelets count (inferior to $25.000 / 4 \mu \mathrm{L}$ ) or active bleeding.

\section{Conclusions}

Data reported in our review are derived from prospective, multinational and multicenter studies and could help clarify similarities and differences in the presentation and outcomes of COVID-19 disease, especially in the presence of thromboembolic disease, also helping to identify strategies for better management in these patients.

We have provided a brief guide to thrombotic disease and antithrombotic therapy during the COVID-19 pandemic, and it could support clinical decision making.

Important considerations for the preventive and therapeutic use of antithrombotic agents must be kept in mind to mitigate thrombotic and haemorrhagic events in these highrisk patients.
All doctors and investigators should work together to create a diagnostic and therapeutic process aimed at early identification of patients with VTE high risk.

This would allow to avoid fatal complications causing a drastic clinical worsening of patients with COVID-19.

\section{Author contributions}

EV, CML, MM designed the research study. EP, GP performed the research. AC, LA provided help and advice on the table and figures; GC, FA, NB, EC analyzed the literature data. All authors contributed to editorial changes in the manuscript. All authors read and approved the final manuscript.

\section{Ethics approval and consent to participate}

Not applicable.

\section{Acknowledgment}

Not applicable.

\section{Funding}

This research received no external funding.

\section{Conflict of interest}

The authors declare no conflict of interest.

\section{References}

[1] WHO. Weekly operational update on COVID-19. 2020. Available at: https://reliefweb.int/sites/reliefweb.int/files/resources/ WOU_2021_26Apr_cleared.pdf (Accessed: 26 April 2021).

[2] Richardson S, Hirsch JS, Narasimhan M, Crawford JM, McGinn $\mathrm{T}$, Davidson KW, et al. Presenting characteristics, comorbidities, and outcomes among 5700 patients hospitalized with COVID-19 in the New York City area. Journal of the American Medical Association. 2020; 323: 2052-2059.

[3] Cimino G, Pascariello G, Bernardi N, Calvi E, Arabia G, Salghetti $\mathrm{F}$, et al. Sinus node dysfunction in a young patient with COVID19. JACC: Case Reports. 2020; 2: 1240-1244.

[4] Pascariello G, Cimino G, Calvi E, Bernardi N, Grigolato M, Garyfallidis $\mathrm{P}$, et al. Cardiogenic shock due to COVID-19-related myocarditis in a 19-year-old autistic patient. Journal of Medical Cases. 2020; 11: 207-210.

[5] Danzi GB, Loffi M, Galeazzi G, Gherbesi E. Acute pulmonary embolism and COVID-19 pneumonia: a random association? European Heart Journal. 2020; 41: 1858.

[6] Ameri P, Inciardi RM, Di Pasquale M, Agostoni P, Bellasi A, Camporotondo $\mathrm{R}$, et al. Pulmonary embolism in patients with COVID19: characteristics and outcomes in the Cardio-COVID Italy multicenter study. Clinical Research in Cardiology. 2020; 1-9.

[7] Bernardi N, Calvi E, Cimino G, Pascariello G, Nardi M, Cani D, et al. COVID-19 pneumonia, takotsubo syndrome, and left ventricle thrombi. JACC: Case Reports. 2020; 2: 1359-1364.

[8] Long X, Zhang Z, Zou W, Ling J, Li D, Jing L, et al. Coagulopathy of Patients with COVID-19 is associated with infectious and inflammatory markers. Risk Management and Healthcare Policy. 2020. 13: 1965-1975.

[9] Liu Y, Yang Y, Zhang C, Huang F, Wang F, Yuan J, et al. Clinical and biochemical indexes from 2019-nCoV infected patients linked to viral loads and lung injury. Science China Life Sciences. 2020; 63: 364-374.

[10] Gralinski LE, Sheahan TP, Morrison TE, Menachery VD, Jensen $\mathrm{K}$, Leist SR, et al. Complement activation contributes to se- 
vere acute respiratory syndrome coronavirus pathogenesis. mBio. 2018; 9: e01753-18.

[11] Dosquet C, Weill D, Wautier JL. Cytokines and thrombosis. Journal of Cardiovascular Pharmacology. 1995; 25: S13-S19.

[12] Sakr Y, Giovini M, Leone M, Pizzilli G, Kortgen A, Bauer M, et al. Pulmonary embolism in patients with coronavirus disease-2019 (COVID-19) pneumonia: a narrative review. Annals of Intensive Care. 2020; 10: 124.

[13] Bompard F, Monnier H, Saab I, Tordjman M, Abdoul H, Fournier L, et al. Pulmonary embolism in patients with COVID-19 pneumonia. European Respiratory Journal. 2020; 56: 2001365.

[14] Poissy J, Goutay J, Caplan M, Parmentier E, Duburcq T, Lassalle F, et al. Pulmonary embolism in patients with COVID-19: awareness of an increased prevalence. Circulation. 2020; 142: 184-186.

[15] Middeldorp S, Coppens M, van Haaps TF, Foppen M, Vlaar AP, Müller MCA, et al. Incidence of venous thromboembolism in hospitalized patients with COVID-19. Journal of Thrombosis and Haemostasis. 2020; 18: 1995-2002.

[16] Sardu C, Gambardella J, Morelli MB, Wang X, Marfella R, Santulli G. Hypertension, thrombosis, kidney failure, and diabetes: is COVID-19 an endothelial disease? A comprehensive evaluation of clinical and basic evidence. Journal of Clinical Medicine. 2020; 9: 1417.

[17] Inciardi RM, Adamo M, Lupi L, Cani DS, Di Pasquale M, Tomasoni $\mathrm{D}$, et al. Characteristics and outcomes of patients hospitalized for COVID-19 and cardiac disease in Northern Italy. European Heart Journal. 2020; 41: 1821-1829.

[18] Llitjos J, Leclerc M, Chochois C, Monsallier J, Ramakers M, Auvray $\mathrm{M}$, et al. High incidence of venous thromboembolic events in anticoagulated severe COVID-19 patients. Journal of Thrombosis and Haemostasis. 2020; 18: 1743-1746.

[19] Klok FA, Kruip MJHA, van der Meer NJM, Arbous MS, Gommers DAMPJ, Kant KM, et al. Incidence of thrombotic complications in critically ill ICU patients with COVID-19. Thrombosis Research. 2020; 191: 145-147.

[20] Lodigiani C, Iapichino G, Carenzo L, Cecconi M, Ferrazzi P, Sebastian $\mathrm{T}$, et al. Venous and arterial thromboembolic complications in COVID-19 patients admitted to an academic hospital in Milan, Italy. Thrombosis Research. 2020; 191: 9-14.

[21] Cui S, Chen S, Li X, Liu S, Wang F. Prevalence of venous thromboembolism in patients with severe novel coronavirus pneumonia. Journal of Thrombosis and Haemostasis. 2020; 18: 14211424.

[22] Al-Samkari H, Karp Leaf RS, Dzik WH, Carlson JCT, Fogerty AE, Waheed A, et al. COVID-19 and coagulation: bleeding and thrombotic manifestations of SARS-CoV-2 infection. Blood. 2020; 136: 489-500.

[23] Piazza G, Campia U, Hurwitz S, Snyder JE, Rizzo SM, Pfeferman $\mathrm{MB}$, et al. Registry of arterial and venous thromboembolic complications in patients with COVID-19. Journal of the American College of Cardiology. 2020; 76: 2060-2072.

[24] Demelo-Rodríguez P, Cervilla-Muñoz E, Ordieres-Ortega L, Parra-Virto A, Toledano-Macías M, Toledo-Samaniego N, et al. Incidence of asymptomatic deep vein thrombosis in patients with COVID-19 pneumonia and elevated D-dimer levels. Thrombosis Research. 2020; 192: 23-26.

[25] Lu Y, Pan L, Zhang W, Cheng F, Hu S, Zhang X, et al. A metaanalysis of the incidence of venous thromboembolic events and impact of anticoagulation on mortality in patients with COVID19. International Journal of Infectious Diseases. 2020; 100: 34-41.

[26] Zhang C, Shen L, Le KJ, Pan MM, Kong LC, Gu ZC, et al. Incidence of venous thromboembolism in hospitalized coronavirus disease 2019 patients: a systematic review and meta-analysis. Frontiers in Cardiovascular Medicine. 2020; 7: 151.

[27] Desai R, Gandhi Z, Singh S, Sachdeva S, Manaktala P, Savani S, et al. Prevalence of pulmonary embolism in COVID-19: a pooled analysis. SN Comprehensive Clinical Medicine. 2020; 1-4.

[28] Porfidia A, Valeriani E, Pola R, Porreca E, Rutjes AWS, Di Nisio M. Venous thromboembolism in patients with COVID-19: sys- tematic review and meta-analysis. Thrombosis Research. 2020; 196: 67-74.

[29] Di Minno A, Ambrosino P, Calcaterra I, Di Minno MND. COVID-19 and venous thromboembolism: a meta-analysis of literature studies. Seminars in Thrombosis and Hemostasis. 2020; 46: 763-771.

[30] Liu F, Li L, Xu M, Wu J, Luo D, Zhu Y, et al. Prognostic value of interleukin-6, C-reactive protein, and procalcitonin in patients with COVID-19. Journal of Clinical Virology. 2020; 127: 104370

[31] Fox SE, Akmatbekov A, Harbert JL, Li G, Quincy Brown J, Vander Heide RS. Pulmonary and cardiac pathology in African American patients with COVID-19: an autopsy series from New Orleans. The Lancet Respiratory Medicine. 2020; 8: 681-686.

[32] Terpos E, Ntanasis-Stathopoulos I, Elalamy I, Kastritis E, Sergentanis TN, Politou M, et al. Hematological findings and complications of COVID-19. American Journal of Hematology. 2020; 95: 834-847.

[33] Huang C, Wang Y, Li X, Ren L, Zhao J, Hu Y, et al. Clinical features of patients infected with 2019 novel coronavirus in Wuhan, China. The Lancet. 2020; 395: 497-506.

[34] Hardy M, Lecompte T, Douxfils J, Lessire S, Dogné JM, Chatelain $\mathrm{B}$, et al. Management of the thrombotic risk associated with COVID-19: guidance for the hemostasis laboratory. Thrombosis Journal. 2020; 18: 17.

[35] Guervilly C, Burtey S, Sabatier F, Cauchois R, Lano G, Abdili E, et al. Circulating endothelial cells as a marker of endothelial injury in severe COVID-19. The Journal of Infectious Diseases. 2020; 222: 1789-1793.

[36] McFadyen JD, Stevens H, Peter K. The emerging threat of (micro)thrombosis in COVID-19 and its therapeutic implications. Circulation Research. 2020; 127: 571-587.

[37] Clark SR, Ma AC, Tavener SA, McDonald B, Goodarzi Z, Kelly MM, et al. Platelet TLR4 activates neutrophil extracellular traps to ensnare bacteria in septic blood. Nature Medicine. 2007; 13: 463469.

[38] Massberg S, Grahl L, von Bruehl M, Manukyan D, Pfeiler S, Goosmann C, et al. Reciprocal coupling of coagulation and innate immunity via neutrophil serine proteases. Nature Medicine. 2010; 16: 887-896.

[39] Fuchs TA, Brill A, Duerschmied D, Schatzberg D, Monestier M, Myers DD, et al. Extracellular DNA traps promote thrombosis. Proceedings of the National Academy of Sciences of the United States of America. 2010; 107: 15880-15885.

[40] Maas C, Renné T. Coagulation factor XII in thrombosis and inflammation. Blood. 2018; 131: 1903-1909.

[41] Zaldivia MTK, McFadyen JD, Lim B, Wang X, Peter K. Plateletderived microvesicles in cardiovascular diseases. Frontiers in Cardiovascular Medicine. 2017; 4: 74.

[42] Assinger A. Platelets and infection-an emerging role of platelets in viral infection. Frontiers in Immunology. 2014; 5: 649.

[43] Skendros P, Mitsios A, Chrysanthopoulou A, Mastellos DC, Metallidis $\mathrm{S}$, Rafailidis $\mathrm{P}$, et al. Complement and tissue factor-enriched neutrophil extracellular traps are key drivers in COVID-19 immunothrombosis. Journal of Clinical Investigation. 2020; 130: 6151-6157.

[44] Nougier C, Benoit R, Simon M, Desmurs-Clavel H, Marcotte G, Argaud L, et al. Hypofibrinolytic state and high thrombin generation may play a major role in SARS-CoV-2 associated thrombosis Journal of Thrombosis and Haemostasis. 2020; 18: 2215-2219.

[45] Chen T, Wu D, Chen H, Yan W, Yang D, Chen G, et al. Clinical characteristics of 113 deceased patients with coronavirus disease 2019: retrospective study. British Medical Journal. 2020; 368: $\mathrm{m} 1091$.

[46] Tang N, Li D, Wang X, Sun Z. Abnormal coagulation parameters are associated with poor prognosis in patient with novel coronavirus pneumonia. Journal of Thrombosis and Haemostasis. 2020; 18: 844-847.

[47] Magro C, Mulvey JJ, Berlin D, Nuovo G, Salvatore S, Harp J, et al. Complement associated microvascular injury and thrombosis in 
the pathogenesis of severe COVID-19 infection: a report of five cases. Translational Research. 2020; 220: 1-13.

[48] Müller F, Mutch NJ, Schenk WA, Smith SA, Esterl L, Spronk HM, et al. Platelet polyphosphates are proinflammatory and procoagulant mediators in vivo. Cell. 2009; 139: 1143-1156.

[49] Cognasse F, Hamzeh-Cognasse H, Lafarge S, Chavarin P, Cogné $\mathrm{M}$, Richard $\mathrm{Y}$, et al. Human platelets can activate peripheral blood $B$ cells and increase production of immunoglobulins. Experimental Hematology. 2007; 35: 1376-1387.

[50] Zhang Y, Xiao M, Zhang S, Xia P, Cao W, Jiang W, et al. Coagulopathy and antiphospholipid antibodies in patients with COVID19. New England Journal of Medicine. 2020; 382: e38.

[51] Hu H, Zhu L, Huang Z, Ji Q, Chatterjee M, Zhang W, et al. Platelets enhance lymphocyte adhesion and infiltration into arterial thrombus. Thrombosis and Haemostasis. 2010; 104: 1184-1192.

[52] Shi S, Qin M, Shen B, Cai Y, Liu T, Yang F, et al. Association of cardiac injury with mortality in hospitalized patients with COVID-19 in Wuhan, China. JAMA Cardiology. 2020; 5: 802-810.

[53] Knowlton KU. Pathogenesis of SARS-CoV-2 induced cardiac injury from the perspective of the virus. Journal of Molecular and Cellular Cardiology. 2020; 147: 12-17.

[54] Dolhnikoff M, Duarte-Neto AN, Almeida Monteiro RA, Silva LFF, Oliveira EP, Saldiva PHN, et al. Pathological evidence of pulmonary thrombotic phenomena in severe COVID-19. Journal of Thrombosis and Haemostasis. 2020; 18: 1517-1519.

[55] Xu P, Zhou Q, Xu J. Mechanism of thrombocytopenia in COVID19 patients. Annals of Hematology. 2020; 99: 1205-1208.

[56] Barnes GD, Burnett A, Allen A, Blumenstein M, Clark NP, Cuker $A$, et al. Thromboembolism and anticoagulant therapy during the COVID-19 pandemic: interim clinical guidance from the anticoagulation forum. Journal of Thrombosis and Thrombolysis. 2020; 50: 72-81.

[57] Samama MM, Cohen AT, Darmon JY, Desjardins L, Eldor A, Janbon C, et al. A comparison of enoxaparin with placebo for the prevention of venous thromboembolism in acutely ill medical patients. Prophylaxis in Medical Patients with Enoxaparin Study Group. The New England Journal of Medicine. 1999; 341: 793800.

[58] Helms J, Tacquard C, Severac F, Leonard-Lorant I, Ohana M, Delabranche $\mathrm{X}$, et al. High risk of thrombosis in patients with severe SARS-CoV-2 infection: a multicenter prospective cohort study. Intensive Care Medicine. 2020; 46: 1089-1098.

[59] McCullough PA, Alexander PE, Armstrong R, Arvinte C, Bain $\mathrm{AF}$, Bartlett RP, et al. Multifaceted highly targeted sequential multidrug treatment of early ambulatory high-risk SARS-CoV-2 infection (COVID-19). Reviews in Cardiovascular Medicine. 2020; 21: $517-530$.

[60] Tang N, Li D, Wang X, Sun Z. Abnormal coagulation parameters are associated with poor prognosis in patients with novel coronavirus pneumonia. Journal of Thrombosis and Haemostasis. 2020; 18: 844-847.

[61] Atallah B, Mallah SI, AlMahmeed W. Anticoagulation in COVID19. European Heart Journal-Cardiovascular Pharmacotherapy. 2020; 6: 260-261.

[62] Ruocco G, McCullough PA, Tecson KM, Mancone M, De Ferrari GM, D'Ascenzo F, et al. Mortality risk assessment using CHA(2)DS(2)-VASc scores in patients hospitalized with coronavirus disease 2019 infection. The American Journal of Cardiology. 2020; 137: 111-117.

[63] Tang N, Bai H, Chen X, Gong J, Li D, Sun Z. Anticoagulant treatment is associated with decreased mortality in severe coronavirus disease 2019 patients with coagulopathy. Journal of Thrombosis and Haemostasis. 2020; 18: 1094-1099.

[64] Paranjpe I, Fuster V, Lala A, Russak AJ, Glicksberg BS, Levin $\mathrm{MA}$, et al. Association of treatment dose anticoagulation with in- hospital survival among hospitalized patients with COVID-19. Journal of the American College of Cardiology. 2020; 76: $122-$ 124.

[65] Casini A, Alberio L, Angelillo-Scherrer A, Fontana P, Gerber B, Graf L, et al. Thromboprophylaxis and laboratory monitoring for in-hospital patients with COVID-19 -a Swiss consensus statement by the Working Party Hemostasis. Swiss Medical Weekly. 2020; 150: w20247.

[66] WHO. Clinical Management of severe acute respiratory infection when novel coronavirus (2019-nCoV) infection is supposed. Interim guidance 28 January 2020. 2020. Available at: (Accessed: 30 May 2020).

[67] Hermans C, Lambert C. Impact of the COVID-19 pandemic on therapeutic choices in thrombosis-hemostasis. Journal of Thrombosis and Haemostasis. 2020; 18: 1794-1795.

[68] Bates SM, Rajasekhar A, Middeldorp S, McLintock C, Rodger MA, James AH, et al. American Society of Hematology 2018 guidelines for management of venous thromboembolism: venous thromboembolism in the context of pregnancy. Blood Advances. 2018; 2: 3317-3359.

[69] Hull RD, Schellong SM, Tapson VF, Monreal M, Samama M, Nicol P, et al. Extended-duration venous thromboembolism prophylaxis in acutely ill medical patients with recently reduced mobility: a randomized trial. Annals of Internal Medicine. 2010; 153: 8-18.

[70] Dentali F, Mumoli N, Prisco D, Fontanella A, Di Minno MND. Efficacy and safety of extended thromboprophylaxis for medically ill patients. A meta-analysis of randomised controlled trials. Thrombosis and Haemostasis. 2017; 117: 606-617.

[71] Spyropoulos AC, Levy JH, Ageno W, Connors JM, Hunt BJ, Iba $\mathrm{T}$, et al. Scientific and standardization committee communication: clinical guidance on the diagnosis, prevention, and treatment of venous thromboembolism in hospitalized patients with COVID19. Journal of Thrombosis and Haemostasis. 2020; 18: 1859-1865.

[72] Spyropoulos AC, Lipardi C, Xu J, Peluso C, Spiro TE, De Sanctis $\mathrm{Y}$, et al. Modified IMPROVE VTE risk score and elevated D-dimer identify a high venous thromboembolism risk in acutely ill medical population for extended thromboprophylaxis. TH Open. 2020; 4: e59-e65.

[73] Pancaldi E, Lazzarini V, D’Alessandro G, Calvi E, Cimino G, Pascariello $\mathrm{G}$, et al. Full endovascular management in simultaneous ischeamic and bleeding complications during Covid 19 pandemic in Northern Italy. Journal of Heart and Cardiology, 2020; 5: 7-9.

[74] Jamil A, Jamil U, Singh K, Khan F, Chi G. Extended thromboprophylaxis with betrixaban or rivaroxaban for acutely ill hospitalized medical patients: meta-analysis of prespecified subgroups. Critical Pathways in Cardiology. 2021; 20: 16-24.

[75] Spyropoulos AC, Levy JH, Ageno W, Connors JM, Hunt BJ, Iba $\mathrm{T}$, et al. Scientific and standardization committee communication: clinical guidance on the diagnosis, prevention and treatment of venous thromboembolism in hospitalized patients with COVID19. Journal of Thrombosis and Haemostasis. 2020; 18: 1859-1865.

[76] Wang J, Hajizadeh N, Moore EE, McIntyre RC, Moore PK, Veress LA, et al. Tissue plasminogen activator (tPA) treatment for COVID-19 associated acute respiratory distress syndrome (ARDS): a case series. Journal of Thrombosis and Haemostasis. 2020; 18: 1752-1755.

[77] Chatterjee S, Chakraborty A, Weinberg I, Kadakia M, Wilensky RL, Sardar P, et al. Thrombolysis for pulmonary embolism and risk of all-cause mortality, major bleeding, and intracranial hemorrhage: a meta-analysis. Journal of the American Medical Association. 2014; 311: 2414-2421.

[78] Risitano AM, Mastellos DC, Huber-Lang M, Yancopoulou D, Garlanda C, Ciceri F, et al. Complement as a target in COVID-19? Nature Reviews Immunology. 2020; 20: 343-344. 